\title{
Severity of COPD at initial spirometry-confirmed diagnosis: data from medical charts and administrative claims
}

This article was published in the following Dove Press journal:

International Journal of COPD

8 November 2011

Number of times this article has been viewed

\author{
Douglas W Mapel' \\ Anand A Dalal² \\ Christopher M Blanchette ${ }^{3,4}$ \\ Hans Petersen ${ }^{3}$ \\ Gary T Ferguson ${ }^{5}$ \\ 'Lovelace Clinic Foundation, \\ Albuquerque, NM, USA; ${ }^{2}$ US Health \\ Outcomes, GlaxoSmithKline, Research \\ Triangle Park, NC, USA; ${ }^{3}$ Lovelace \\ Respiratory Research Institute, \\ Kannapolis, NC, USA; ${ }^{4}$ University \\ of North Carolina Eshelmen School \\ of Pharmacy, Chapel Hill, NC, USA; \\ ${ }^{5}$ Pulmonary Research Institute of \\ Southeast Michigan, Livonia, MI, USA
}

Correspondence: Douglas W Mapel Lovelace Clinic Foundation, 2309 Renard Place SE, Suite I03, Albuquerque, NM 87I06, USA

Tel +l 5059389900

$\mathrm{Fax}+\mathrm{I} 5059389940$

Email doug.mapel@Icfresearch.org
Purpose: This study was conducted to determine COPD severity at the time of diagnosis as confirmed by spirometry in patients treated in a US managed care setting.

Patients and methods: All patients with one or more inpatient stays, one or more emergency department visits, or two or more outpatient visits with diagnosis codes for COPD during 1994-2006 were identified from the Lovelace Patient Database. From this group, a subset of continuously enrolled patients with evidence in claims of a first available pulmonary function test or pulmonary clinic visit and a confirmatory claim for a COPD diagnosis was selected. Medical chart abstraction was undertaken for this subset to gather information for diagnosis and severity staging of each patient based on the Global Initiative for Chronic Obstructive Lung Disease (GOLD) criteria for COPD.

Results: Of the 12,491 patients with a primary or secondary COPD diagnosis between 1994 and 2006, there were 1520 continuously enrolled patients who comprised the study cohort. Among the 648 eligible records from patients with evidence of a pulmonary function test, 366 were identified by spirometry as having COPD of GOLD stage I or higher (average percentage of predicted forced expiratory volume in 1 second: 60\%): 19\% were diagnosed at the stage of mild disease (GOLD stage I); 50\% at moderate disease (GOLD stage II); and 31\% at severe or very severe disease (GOLD stage III or IV, respectively). The majority of patients in these groups were not receiving maintenance treatment.

Conclusion: The results demonstrate a very low incidence of early-stage diagnosis, confirmed by a pulmonary function test, of COPD in a large US sample and support calls for increased screening for COPD and treatment upon diagnosis.

Keywords: lung function, Global Initiative for Chronic Obstructive Lung Disease (GOLD), detection, early treatment

\section{Introduction}

COPD is characterized by chronic airflow limitation caused by inflammation-mediated damage to lung tissue that is not fully reversible. ${ }^{1}$ COPD follows a slowly progressive course whereby increasing airflow limitation impairs the general health and functional ability of the patient. While the course of COPD has historically been viewed as refractory to therapeutic intervention, recent studies suggest that the course of COPD can be modified..$^{2-10}$ For example, smoking cessation can slow the rate of decline in lung function and improve survival. ${ }^{6}$ Furthermore, in large, randomized trials, pharmacotherapeutic intervention has been associated with sustained improvement in symptoms, exercise capacity, and overall health status and reductions in the frequency of exacerbations and the rate of decline of lung function..$^{7-11}$ On the basis of these 
data and others, the 2009 update of the Global Initiative for Chronic Obstructive Lung Disease (GOLD) guidelines characterizes COPD as a treatable disease and states that "early diagnosis and implementation of treatment ... have been demonstrated to prevent or delay the onset of airflow limitation or reduce its progression."1

As in other chronic diseases, early diagnosis in its course and early intervention, when symptoms are mild, are thought to be critical for maximizing the probability of good therapeutic outcomes in COPD. ${ }^{5}$ While previous clinical trials of pharmacotherapeutic intervention have primarily been conducted in patients with severe or very severe disease, significant benefits have also been documented in patients with milder disease. In a recently published, prespecified subgroup analysis of data from the randomized, double-blind, placebocontrolled UPLIFT (Understanding Potential Long-Term Impacts on Function with Tiotropium) trial, pharmacotherapy compared with placebo significantly reduced the rate of decline of post-bronchodilator forced expiratory volume in 1 second $\left(\mathrm{FEV}_{1}\right)$, improved health status, and prolonged the time to first exacerbation and to exacerbation resulting in hospitalization over 4 years in patients with GOLD stage II (moderate) disease. ${ }^{10}$ Similarly, in a post hoc analysis of data from the randomized, double-blind, placebo-controlled TORCH (Towards a Revolution in COPD Health) trial, pharmacotherapy compared with placebo significantly reduced moderate to severe exacerbations and improved health status and $\mathrm{FEV}_{1}$ in patients with GOLD stage II (moderate) disease. ${ }^{12}$

Approximately half of patients who suffer from COPD remain undiagnosed, ${ }^{12}$ and only $30 \%-50 \%$ of newly diagnosed patients have their diagnosis confirmed by spirometry. ${ }^{13}$ Expert opinion suggests that most COPD patients are not diagnosed until advanced stages of the disease - that early disease, in particular, often goes unrecognized because it is manifested by mild and often subtle signs and symptoms. ${ }^{2,13}$ However, severity at the time of diagnosis has not been systematically evaluated in epidemiologic research. This study was conducted to determine COPD severity at the time of initial spirometry-confirmed COPD diagnosis in a large sample of patients in the Lovelace Health Plan.

\section{Material and methods}

\section{Data source}

With institutional review board approval, data were obtained from the Lovelace Patient Database, a longitudinal, managed care data repository that includes information on demographics, enrollment, inpatient and outpatient claims, pharmacy fills, and clinical laboratory values for a managed care population in New
Mexico of approximately 250,000 members (Lovelace Health System/Lovelace Health Plan, a staff- and network-model health maintenance organization [HMO]). The database currently contains approximately 13 years of health care data that are cross-linked in relational files so that complete episodes of care and longitudinal data for cases/controls, cohorts, and broader populations are available for research. Staff responsible for maintaining and administering the database communicate regularly with clinicians, medical coders, and medical record specialists to help ensure that data used for research are interpreted correctly and to gain insight into organizational norms, physician practice patterns, coding practices, and data validity.

\section{Sample selection and severity staging}

All patients with one or more inpatient stays, one or more emergency department visits, or two or more outpatient visits with diagnosis codes for COPD (ie, primary or secondary diagnosis of COPD defined using International Classification of Disease, Ninth Revision, Clinical Modification [ICD-9-CM] codes 491.x, 492.x, 496.x) from 1994 through 2006 were identified from the Lovelace Patient Database (Figure 1). From this group, a subset of continuously enrolled patients with evidence in claims of an initial pulmonary function test or a pulmonary clinic visit (using procedural codes) was selected. For these patients with one or more instances of a COPD diagnosis code in claims as well as evidence of spirometry in claims, the initial pulmonary function test date was considered the index date at which COPD diagnosis was confirmed using objective clinical data. Some of these patients may have had a COPDcoded medical claim preceding the initial pulmonary function test. However, because the objective of the study was to ascertain COPD severity at the first objectively confirmed COPD diagnosis, the initial pulmonary function test date was considered the COPD diagnosis index date. Medical chart abstraction was undertaken for this subset of patients to gather information sufficient to permit "diagnosis" and severity staging of each patient based on the GOLD criteria for COPD (Table 1). ${ }^{1}$ Information gathered from the pulmonary clinic charts included pulmonary function test values, smoking history, height, and weight. The clinic visit chart entries for abstraction were selected by targeting the two most recent visits prior to the COPD-coded encounter in the claims data. Post-bronchodilator spirometry was used in defining severity stages from medical charts.

The frequencies of asthma, cardiovascular disease, and depression - comorbidities commonly associated with $\mathrm{COPD}^{1}$ were assessed as a function of COPD severity. Comorbidity 


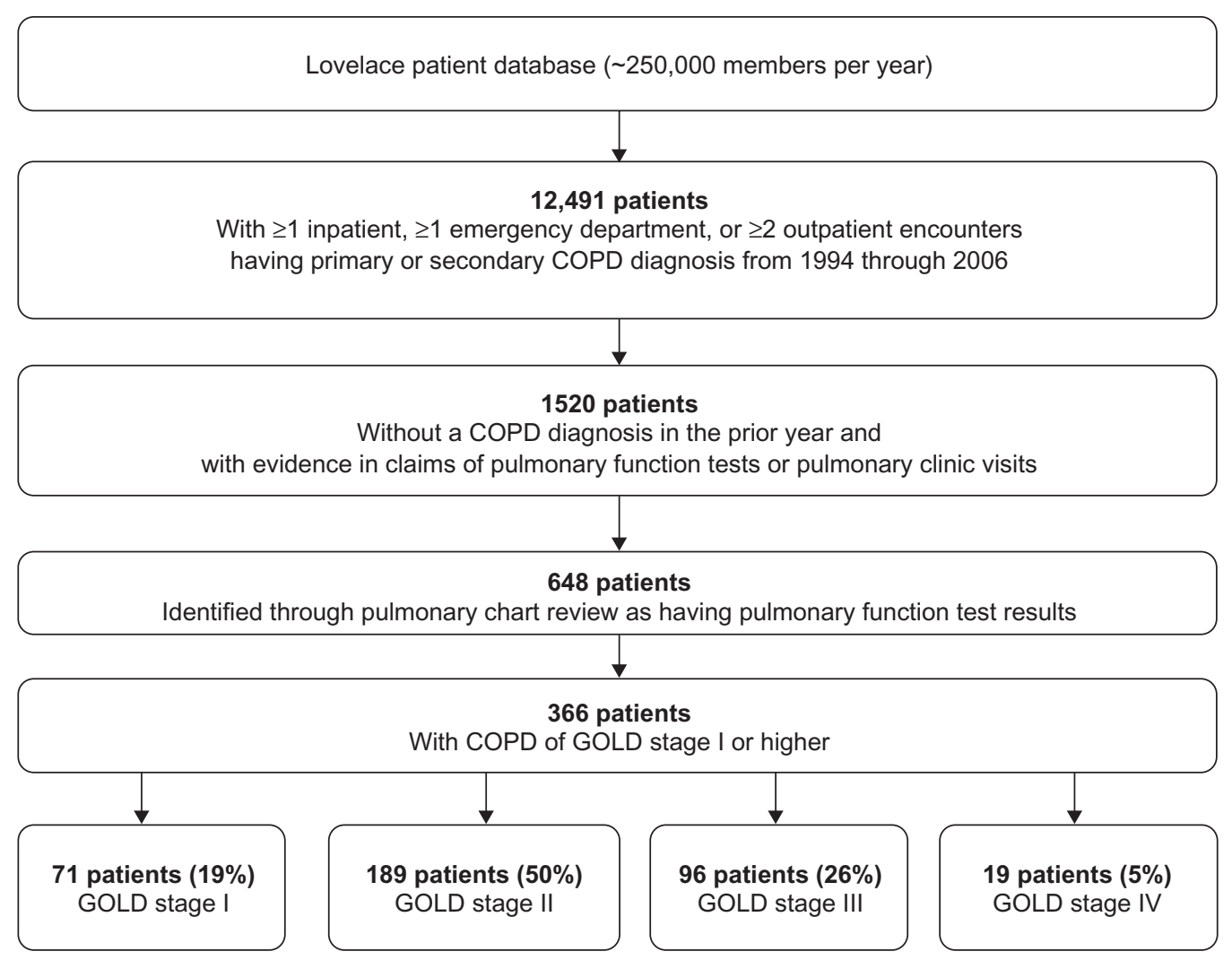

Figure I Sample selection and incident COPD cases.

Abbreviation: GOLD, Global Initiative for Chronic Obstructive Lung Disease.

was considered to be present if one or more medical claims for the relevant diagnosis code were identified during the year after the initial pulmonary function test. The frequency of prescription of COPD-related pharmacotherapy as a function of COPD severity was determined at diagnosis as well as after the pulmonary function test date by identifying pharmacy claims for oral corticosteroids or antibiotics, any maintenance treatment, or rescue medication. Maintenance treatment included anticholinergics, inhaled corticosteroids, long-acting beta agonists, or the combination of an inhaled corticosteroid and a long-acting beta agonist. Inhaled corticosteroids included flunisolide, mometasone, triamcinolone, beclomethasone, budesonide, dexamethasone, and fluticasone propionate. Long-acting beta agonists included formoterol and salmeterol. Rescue therapy included was albuterol. These pharmacy claims were extracted from the Lovelace claims database on or after the initial pulmonary function test date.

Data were summarized with descriptive statistics. No hypothesis testing was undertaken. GOLD stage III (severe) and IV (very severe) categories were collapsed for the summaries of frequencies of comorbidities and COPDrelated medications by COPD severity.

Table I Global Initiative for Chronic Obstructive Lung Disease (GOLD) criteria for classification of COPD'

\begin{tabular}{|c|c|c|c|}
\hline GOLD stage & Descriptor & Signs and symptoms & $\begin{array}{l}\text { Spirometry results based on } \\
\text { post-bronchodilator FEV, }\end{array}$ \\
\hline $\mathrm{I}$ & Mild & $\begin{array}{l}\text { Mildly reduced airflow; sometimes a chronic } \\
\text { cough and sputum production }\end{array}$ & $\begin{array}{l}\mathrm{FEV}_{1} / \mathrm{FVC}<70 \\
\mathrm{FEV}_{1} \geq 80 \% \text { predicted }\end{array}$ \\
\hline II & Moderate & $\begin{array}{l}\text { Worsening airflow; shortness of breath typically } \\
\text { brought on by exertion }\end{array}$ & $\begin{array}{l}\mathrm{FEV}_{1} / \mathrm{FVC}<70 \\
50 \% \leq \mathrm{FEV}_{1}<80 \% \text { predicted }\end{array}$ \\
\hline III & Severe & $\begin{array}{l}\text { Further worsening airflow; greater shortness } \\
\text { of breath; reduced quality of life }\end{array}$ & $\begin{array}{l}\mathrm{FEV}_{1} / \mathrm{FVC}<70 \\
30 \% \leq \mathrm{FEV}_{1}<50 \% \text { predicted }\end{array}$ \\
\hline IV & Very severe & $\begin{array}{l}\text { Severe reduction of airflow; chronic respiratory } \\
\text { failure; greatly reduced quality of life }\end{array}$ & $\begin{array}{l}\mathrm{FEV}_{1} / \mathrm{FVC}<70 \\
\mathrm{FEV}_{1}<30 \% \text { predicted or } \mathrm{FEV}_{1}<50 \% \\
\text { predicted plus chronic respiratory failure }\end{array}$ \\
\hline
\end{tabular}

Abbreviations: $\mathrm{FEV}_{\mathrm{l}}$, forced expiratory volume in I second; FVC, forced vital capacity. 


\section{Results}

\section{Sample}

Figure 1 shows the derivation of the study sample. The Lovelace Patient Database showed 12,491 patients had one or more inpatient, one or more emergency department, or two or more outpatient encounters with a primary or secondary COPD diagnosis (ICD-9-CM codes 491.x, 492.x, 496.x) between 1994 and 2006. Of those 12,491 patients, there were 1520 continuously enrolled patients with evidence of either a pulmonary function test or a pulmonary clinic visit who comprised the study cohort. Pulmonary function test results and other data necessary for ascertaining GOLD status were available from charts for 648 of these 1520 patients; charts for the remainder were not available because of issues with archiving and off-site storage. Of the 648 patients for whom pulmonary function test results were available, 366 were classified at their initial pulmonary clinic spirometry assessment as having confirmed COPD of GOLD stage I or higher (Figures 1 and 2). The overall average percentage of predicted $\mathrm{FEV}_{1}$ (post-bronchodilator) at the initial pulmonary function test was $60 \%$ for these 366 patients.

Among the 648 patients for whom pulmonary function test results were available, $273(42 \%)$ had a COPD encounter in the pre-index year. The majority (approximately 90\%) of COPD medical claims for these 648 patients were associated with a physician office visit, as opposed to an emergency department visit or hospitalization.

Among the 366 patients with spirometry-confirmed COPD of GOLD stage I or higher at their initial pulmonary clinic spirometry assessment, 279 (76.2\%) had a COPD diagnosis-coded encounter at some time prior to their pulmonary function test; $41 \%$ had a COPD diagnosis-coded

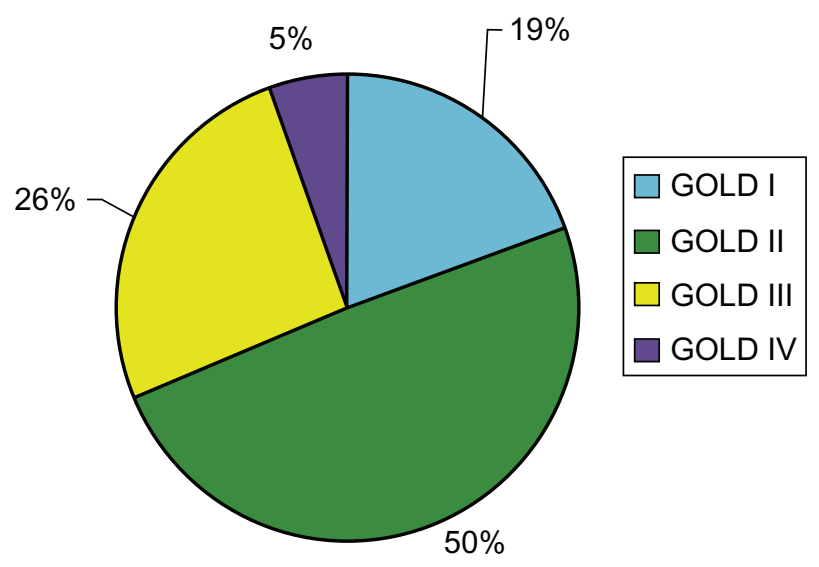

Figure 2 COPD severity at initial spirometry-confirmed diagnosis in patients with COPD of Global Initiative for Chronic Obstructive Lung Disease (GOLD) stage I or higher $(n=366)$. encounter in the year prior to the pulmonary function test. Only $25 \%$ of the 366 patients with spirometry-confirmed COPD of GOLD stage I or higher were initially diagnosed at pulmonary specialist offices; primary care settings accounted for the majority of the diagnosis claims.

\section{Severity of incident COPD cases at initial spirometry-confirmed COPD diagnosis}

Of the 648 patients for whom pulmonary function test results were available, 282 could be classified either as having normal spirometry $\left(\mathrm{FEV}_{1} /\right.$ forced vital capacity $[\mathrm{FVC}] \geq 0.7$ and percentage of predicted $\mathrm{FEV}_{1} \geq 80 \%$ ) or as being "restricted" $\left(\mathrm{FEV}_{1} / \mathrm{FVC} \geq 0.7\right.$ and percentage of predicted $\mathrm{FEV}_{1}<80 \%$ ). At the time of spirometry-confirmed COPD diagnosis, the majority of the remaining 366 patients with GOLD stage I or higher were assigned a GOLD stage reflecting moderate, severe, or very severe disease (Figures 1 and 2). Stage II (moderate) disease was present in $50 \%$ of patients; stage III (severe) disease in $26 \%$; and stage IV (very severe) in 5\% (Figure 1).

\section{Demographics and comorbidities by severity at initial spirometry-confirmed COPD diagnosis}

Table 2 shows demographics and comorbidities for all 648 patients for whom pulmonary function test results were available. Among the 366 patients with COPD of GOLD stage I or higher, the majority of patients were $\geq 65$ years of age at the time of diagnosis, and mean age at diagnosis was similar across the severity groups. The majority of patients with GOLD stage I (mild) disease at diagnosis were male $(81.7 \%)$, whereas males accounted for the minority of patients with GOLD stage II (moderate), III (severe), or IV (very severe) disease. The likelihood of being underweight increased with increasing COPD severity; $15.8 \%$ of patients with GOLD stage IV (very severe) disease were underweight. The mean number of cigarette pack years was greater for those with GOLD stage III (severe) or IV (very severe) disease than for those with less severe disease, and those with GOLD stage III or IV disease were more likely than those with less severe disease to be smoking at the time of diagnosis.

Of the comorbidities assessed, asthma and cardiovascular disease (dyslipidemia, angina, congestive heart disease, evidence of cardiac stents, coronary artery bypass graft, ischemic heart disease, other cardiac conditions defined) were the most common. An asthma-related claim during the year prior to COPD diagnosis was found in $23 \%$ of patients with 
Table 2 Demographics and baseline characteristics from medical charts for 648 Lovelace members including patients with COPD ( $n$ = 366; Global Initiative for Chronic Obstructive Lung Disease [GOLD] definition) at initial pulmonary function test

\begin{tabular}{|c|c|c|c|c|c|c|}
\hline Variable & $\begin{array}{l}\text { Normal } \\
\text { spirometry } \\
(n=138)\end{array}$ & $\begin{array}{l}\text { Restricted } \\
\text { spirometry } \\
(n=144)\end{array}$ & $\begin{array}{l}\text { GOLD stage } I \text {, } \\
\text { mild } \\
(n=7 I)\end{array}$ & $\begin{array}{l}\text { GOLD stage II, } \\
\text { moderate } \\
(n=180)\end{array}$ & $\begin{array}{l}\text { GOLD stage III, } \\
\text { severe } \\
(n=96)\end{array}$ & $\begin{array}{l}\text { GOLD stage IV, } \\
\text { very severe } \\
(n=19)\end{array}$ \\
\hline Mean age [years (SD)] & $7 I(12.7)$ & $68(21.8)$ & $73(10.7)$ & $71(9.5)$ & $69(9.8)$ & $66(15.0)$ \\
\hline \multicolumn{7}{|l|}{ Age group [n (\%)] } \\
\hline$<40$ years & $2(1.4)$ & $4(2.8)$ & $0(0)$ & $0(0)$ & $\mathrm{I}(\mathrm{I} .0)$ & I (5.3) \\
\hline 40-49 years & $9(6.5)$ & $14(9.7)$ & $3(4.2)$ & $4(2.2)$ & $\mathrm{I}(\mathrm{I} .0)$ & $2(10.5)$ \\
\hline 50-64 years & $29(21.0)$ & $34(23.6)$ & $12(16.9)$ & $37(20.6)$ & $26(27.1)$ & $3(15.8)$ \\
\hline$\geq 65$ years & $98(71.0)$ & $92(63.9)$ & $56(79.8)$ & $139(77.2)$ & $68(70.8)$ & $13(68.4)$ \\
\hline \multicolumn{7}{|l|}{$\operatorname{Sex}[\mathrm{n}(\%)]$} \\
\hline Male & 81 (58.7) & $4 \mathrm{I}(28.5)$ & $58(81.7)$ & $77(42.8)$ & $29(30.2)$ & $7(36.8)$ \\
\hline Female & $57(4 \mid .3)$ & 103 (7I.5) & $13(18.3)$ & $103(57.2)$ & $67(69.8)$ & $12(63.2)$ \\
\hline \multicolumn{7}{|l|}{ Weight status* [n (\%)] } \\
\hline Underweight & $\mathrm{I}(0.7)$ & $5(3.5)$ & $0(0.0)$ & $6(3.3)$ & $7(7.3)$ & $3(15.8)$ \\
\hline Normal weight & $49(35.5)$ & $30(20.8)$ & $25(35.2)$ & $52(28.9)$ & $39(40.6)$ & $10(52.6)$ \\
\hline Overweight & $46(33.3)$ & $39(27.1)$ & $32(45.1)$ & $72(40.0)$ & $32(33.3)$ & $3(I 5.8)$ \\
\hline Obese & $44(31.9)$ & $72(50.0)$ & $14(19.7)$ & $53(29.4)$ & $20(20.8)$ & $3(15.8)$ \\
\hline Mean BMI $\left[\mathrm{kg} / \mathrm{m}^{2}(\mathrm{SD})\right]$ & $27.7(4.9)$ & $30.7(8.1)$ & $26.9(3.8)$ & $28.40(7.0)$ & $26.4(6.4)$ & $23.1(5.4)$ \\
\hline Current smoker [n (\%)] & $24(17.4)$ & $31(21.5)$ & $12(16.9)$ & $38(21.1)$ & $25(26.0)$ & $5(26.3)$ \\
\hline Mean cigarette pack years (SD) & $23(26.7)$ & $25.4(26.6)$ & $36.6(21.9)$ & $36.1(25.4)$ & $40.0(26.9)$ & $47.7(32.2)$ \\
\hline
\end{tabular}

Note: *Underweight, $16.5-18.4 \mathrm{~kg} / \mathrm{m}^{2}$; normal weight, $18.5-24.9 \mathrm{~kg} / \mathrm{m}^{2}$; overweight, $25-30 \mathrm{~kg} / \mathrm{m}^{2}$; obese, $\geq 30.1 \mathrm{~kg} / \mathrm{m}^{2}$.

Abbreviations: BMI, body mass index; SD, standard deviation.

GOLD stage I (mild) disease, $43 \%$ of patients with GOLD stage II (moderate) disease, and $42 \%$ of patients with GOLD stage III (severe) or IV (very severe) disease (Figure 3). The frequency of cardiovascular disease ranged from $13 \%$ to $21 \%$ across severity groups. The frequencies of the other comorbidities assessed were too low in each severity group to permit conclusions.

\section{Medications}

As Figure 4 shows, at the time of initial spirometryconfirmed COPD diagnosis among the 366 patients with GOLD stage I disease, less than half of patients across severity categories and only $43 \%$ of those with GOLD stage III (severe) or IV (very severe) disease were prescribed a maintenance therapy for COPD. Patients with GOLD stage III (severe) or IV (very severe) disease were more likely to be prescribed maintenance therapy at initial diagnosis compared with patients with milder forms of the disease. Likewise, patients with GOLD stage III (severe) or IV (very severe) disease were more likely to be prescribed a rescue medication. The frequency of being prescribed oral corticosteroids or antibiotics was similar across severity groups.

Table 3 shows the frequency of pharmacy claims for maintenance and rescue medications during the year after the index pulmonary function for all 648 patients for whom pulmonary function tests were available. Less than $30 \%$ of those with spirometry-confirmed diagnosis of mild or moderate COPD received maintenance treatment, and less than $50 \%$ of those with spirometry-confirmed diagnosis of severe or very severe disease received maintenance treatment.

\section{Discussion}

In this study, COPD severity was characterized at the time of initial diagnosis as confirmed by spirometry by examining medical charts for patients with COPD who were continuously enrolled in a closed-network HMO setting. Longitudinal administrative claims data and medical chart data were linked in the Lovelace Health Plan. While claims data are usually very robust and reliable, the potential exists for misclassification or coding error. Misclassification errors are a limitation in any survey of COPD patients. The GOLD guidelines specifically mention asthma, congestive heart failure, bronchiectasis, tuberculosis, obliterative bronchiolitis, and diffuse panbronchiolitis in the differential diagnosis of COPD. In the current study, severity at initial spirometryconfirmed COPD was documented and post-bronchodilator spirometry values were used to categorize patients into severity stages using GOLD classifications. This approach avoided the limitation, common to many observational studies that use ICD-9-CM codes to identify COPD patients within claims, of lack of objective spirometric confirmation of COPD diagnosis. In the large US managed care population 


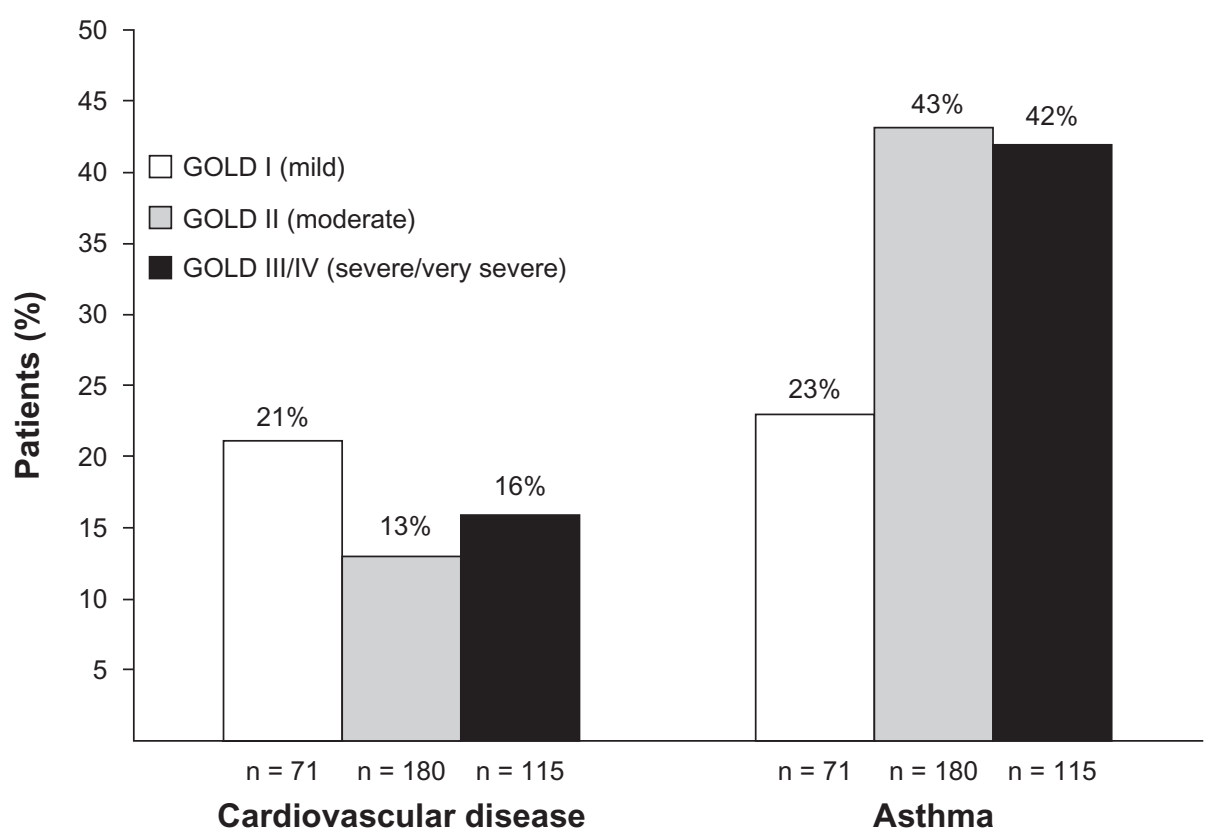

Figure 3 Proportion of patients with selected comorbidities by disease severity. Abbreviation: GOLD, Global Initiative for Chronic Obstructive Lung Disease.

assessed in the current study, a minority of patients with COPD were diagnosed at the stage of mild disease: only $19 \%$ of patients with an initial diagnosis between 1994 and 2006 had mild COPD (GOLD stage I) based on spirometry at the time of diagnosis. One in three patients $(31 \%)$ with an initial diagnosis based on spirometry had severe or very severe disease (GOLD stage III or IV, respectively) at the time of diagnosis. The results suggest that COPD severity is underestimated, with a resultant delay in diagnosis, and they provide objective data that support the recommendation for screening programs that can detect COPD at earlier stages of the disease. ${ }^{2,13}$

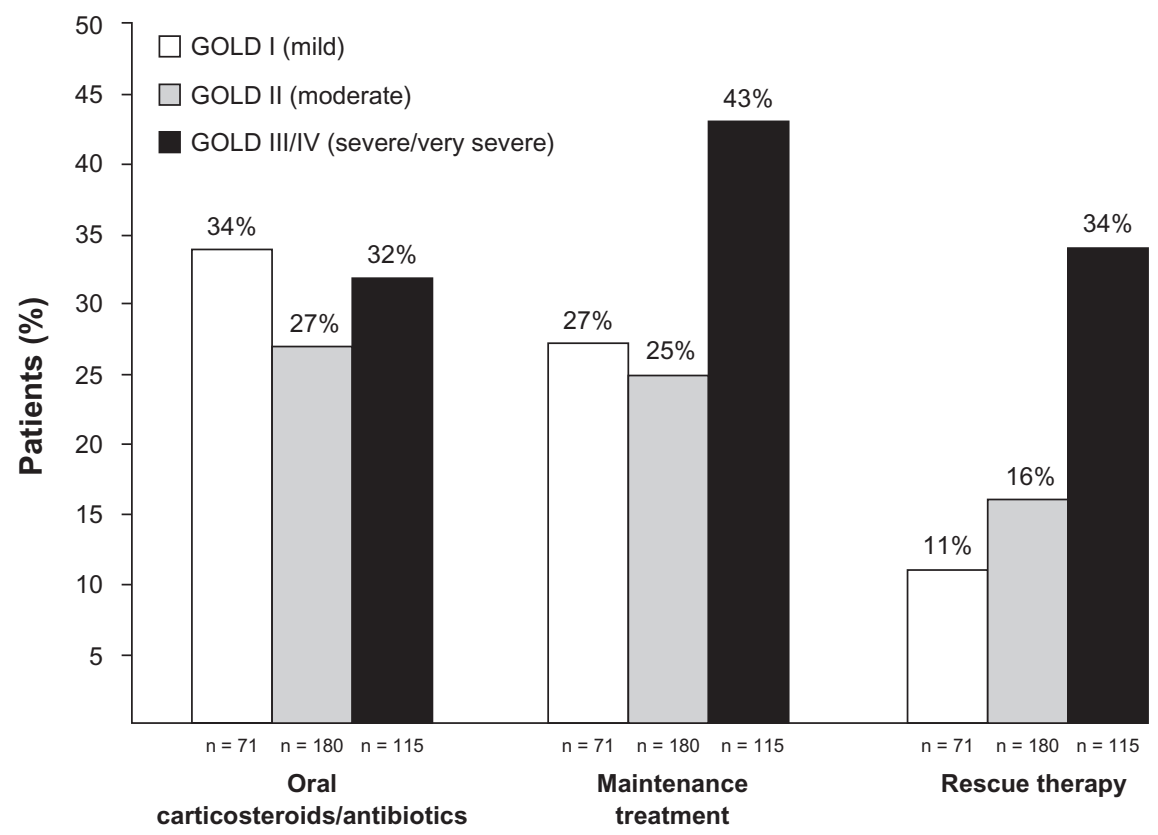

Figure 4 Proportion of patients prescribed COPD-related medications at initial diagnosis.

Notes: Maintenance treatment included anticholinergics, inhaled corticosteroids, long-acting beta agonists, or the combination of an inhaled corticosteroid and a long-acting beta agonist; rescue therapy was albuterol.

Abbreviation: GOLD, Global Initiative for Chronic Obstructive Lung Disease. 
Table 3 Frequency of pharmacy use over I year post index for 648 COPD patients by Global Initiative for Chronic Obstructive Lung Disease (GOLD) stage

\begin{tabular}{|c|c|c|c|c|c|c|}
\hline Variable & $\begin{array}{l}\text { Normal } \\
\text { spirometry } \\
\text { [n (\%)] }\end{array}$ & $\begin{array}{l}\text { Restricted } \\
\text { spirometry } \\
{[n(\%)]}\end{array}$ & $\begin{array}{l}\text { GOLD stage I, } \\
\text { mild } \\
{[n(\%)]}\end{array}$ & $\begin{array}{l}\text { GOLD stage II, } \\
\text { moderate } \\
{[\mathrm{n}(\%)]}\end{array}$ & $\begin{array}{l}\text { GOLD stage III, } \\
\text { severe } \\
{[\mathrm{n}(\%)]}\end{array}$ & $\begin{array}{l}\text { GOLD stage IV, } \\
\text { very severe } \\
\text { [n (\%)] }\end{array}$ \\
\hline Total number of patients & $138(100.0)$ & $144(100.0)$ & $71(100.0)$ & $180(100.0)$ & $96(100.0)$ & $19(100.0)$ \\
\hline No treatment* & $98(7 I)$ & $89(61.8)$ & $40(56.3)$ & $103(57.2)$ & $44(45.8)$ & II (57.9) \\
\hline Antibiotic/oral corticosteroid & $31(22.5)$ & $48(33.3)$ & $24(33.8)$ & $49(27.2)$ & $33(34.4)$ & $4(21.1)$ \\
\hline Maintenance treatment ${ }^{\dagger}$ & $21(15.2)$ & $23(16.0)$ & $20(28.2)$ & $48(26.7)$ & $42(43.8)$ & $8(42.1)$ \\
\hline Rescue therapy $\ddagger$ & $10(7.2)$ & $19(13.2)$ & $8(\mathrm{II} .3)$ & $28(15.6)$ & $35(36.5)$ & $4(2 I . I)$ \\
\hline
\end{tabular}

Notes: *Patients may use drugs from multiple categories: percentages shown are not additive for antibiotic/oral corticosteroid, maintenance treatment, or rescue therapy;

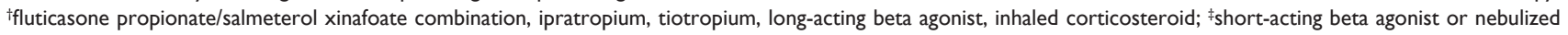
short-acting beta agonist.

One of the most important findings of this study was that patients with COPD of GOLD stage I or higher $(\mathrm{n}=366)$ had an average percentage of predicted $\mathrm{FEV}_{1}$ of $60 \%$ at the time of initial spirometry. That the percentage of predicted $\mathrm{FEV}_{1}$ values reflected borderline severe disease at the time of initial diagnosis reflects a significant delay in recognition of COPD. Many (76\%) of the 366 patients with COPD of GOLD stage I or higher had medical claims with COPD ICD-9-CM codes in the period preceding their initial COPDconfirming pulmonary function test, and most of the medical encounters occurred in the primary care setting. This pattern of findings suggests that COPD is rarely confirmed using spirometry in primary care and is consistent with the previous observation that only $30 \%-50 \%$ of newly diagnosed patients have their diagnosis confirmed by spirometry. ${ }^{13}$ The results of this study, which is to the authors' knowledge among the first to quantify the delayed diagnosis of COPD, are consistent with perceptions of the progressive nature of undiagnosed COPD and they underscore the need for improvement in the diagnosis and management of this chronic progressive disease.

At this time, effective early detection methods for COPD are still in development. Spirometry is necessary to confirm a diagnosis of COPD. However, the cost and logistics of spirometry render it impractical as a population-based screening tool in many health care settings. ${ }^{14}$ Alternatives to spirometry are needed to screen patients for COPD. Several tools to screen for COPD have been developed. ${ }^{15-22}$ For example, the five-item Lung Function Questionnaire, designed to identify patients appropriate for spirometryconfirmed diagnostic evaluation for COPD, has recently been validated..$^{15,16}$ This instrument is suitable for use in both primary and specialist care.

Males accounted for the majority of patients with GOLD stage I (mild) disease at diagnosis and for the minority of patients with GOLD stage II (moderate), III (severe), or IV (very severe) disease. The basis for the difference in sex distribution by severity at diagnosis is unknown. In a systematic review and meta-analysis of studies conducted in 28 countries from 1990 to 2004, the prevalence rate of COPD (GOLD stage I and higher) was higher in men than in women. ${ }^{23}$ In the US, the incidence of COPD is growing faster among women, although the most recent surveys suggest the prevalence rate is still higher in men. ${ }^{1}$ The late presentation of COPD in this population could reflect the traditional perception among clinicians that COPD is a man's disease. The possible influence of gender on severity at diagnosis warrants additional study in other health care settings.

Comorbidities can affect the severity of COPD and its overall impact on the patient; therefore, comorbidities should influence therapeutic management. ${ }^{1}$ Patients with COPD are at heightened risk for myocardial infarction, angina, osteoporosis, respiratory infection, bone fractures, depression, and diabetes. ${ }^{1}$ COPD may contribute to some of these comorbidities via its extrapulmonary effects such as malnutrition and skeletal muscle dysfunction. ${ }^{1}$ In the current study, asthma and cardiovascular disease were the most prevalent comorbidities - a result consistent with previous findings. ${ }^{1,24}$ While the incidence of asthma was particularly high in patients with moderate or more severe COPD, more than $40 \%$ of whom had asthma, it was also common among patients with mild COPD, $23 \%$ of whom had asthma. These findings underscore the importance of assessing patients with COPD for other respiratory comorbidities, particularly asthma, regardless of COPD severity.

The results of this study should be interpreted in the context of its limitations. First, records of more than half of the 1520 patients with evidence of pulmonary function tests or a pulmonary clinic visit were excluded from the evaluation for COPD diagnosis and severity staging because of insufficient 
pulmonary chart data (due to issues with archiving and storage). Exclusion of these records might have resulted in selection bias if the excluded records differed systematically in some way from the records that were included. Another limitation of the study is possible lack of generalizability of the results from the Lovelace Health Plan, a closed-network HMO plan, to other commercial health plans prevalent in the US.

\section{Conclusion}

The results of this study demonstrate a very low incidence of early-stage spirometry-confirmed diagnosis of COPD in a large US sample and they support calls for increased screening for COPD. ${ }^{13}$ The majority of these patients with COPD of GOLD stage I or higher were moderate to severe, as defined by GOLD guidelines. This study found that a substantial number of patients without prior history of spirometry had already progressed to advanced stages of disease. Furthermore, once diagnosed using spirometry, a low proportion of patients received maintenance treatment, revealing a possible opportunity to improve care.

\section{Acknowledgments}

Each author participated in the research and the data analysis. Each author was involved in planning the manuscript content and in critical review and revision of the manuscript. Also, each author reviewed and approved the manuscript as submitted. The authors acknowledge Jane Saiers, PhD (The WriteMedicine, Inc), for assistance with writing this manuscript. Dr Saiers prepared the first draft. GlaxoSmithKline funded Dr Saiers' work. Ann Von Worley, BSN, assisted with abstraction of the medical records.

\section{Disclosure}

Dr Mapel has received research funding from and served as a consultant for GlaxoSmithKline, Pfizer Pharmaceuticals, Boehringer Ingelheim, and AstraZeneca. Dr Ferguson has served as a consultant for GlaxoSmithKline, Boehringer Ingelheim, AstraZeneca, Novartis, and Pearl Therapeutics; spoken on behalf of GlaxoSmithKline, Boehringer Ingelheim, and AstraZeneca; and received research funding from GlaxoSmithKline, Boehringer Ingelheim, Forest Pharmaceuticals, and Novartis. Dr Blanchette has received research support from and served as consultant for GlaxoSmithKline, AstraZeneca LP, Sepracor, Viostat, Wyeth, Schering-Plough, Premier, and NovoNordisk. Mr Petersen has received research support from GlaxoSmithKline, AstraZeneca LP, Premier, and Wyeth.

\section{References}

1. Global Initiative for Chronic Obstructive Lung Disease. Global strategy for the diagnosis, management, and prevention of chronic obstructive pulmonary disease (updated 2010). Available from: http://www.goldcopd.org/uploads/users/files/GOLDReport_April112011.pdf. Accessed October 19, 2011.

2. Radin A, Cote C. Primary care of the patient with chronic obstructive pulmonary disease: part 1 , frontline prevention and early diagnosis. $\mathrm{Am}$ J Med. 2008;121(7 Suppl):S3-S12.

3. Celli BR. Chronic obstructive pulmonary disease: from unjustified nihilism to evidence-based optimism. Proc Am Thorac Soc. 2006;3(1): 58-65.

4. Celli BR. Update on the management of COPD. Chest. 2008;133(6): 1451-1462.

5. Cooper CB, Dransfield M. Primary care of the patient with chronic obstructive pulmonary disease: part 4, understanding the clinical manifestations of a progressive disease. Am J Med. 2008;121(7 Suppl): S33-S45.

6. Godtfredsen NS, Lam TH, Hansel TT, et al. COPD-related morbidity and mortality after smoking cessation: status of the evidence. Eur Respir J. 2008;32(4):844-853.

7. Calverley PM, Anderson JA, Celli B, et al. Salmeterol and fluticasone propionate and survival in chronic obstructive pulmonary disease. N Engl J Med. 2007;356(8):775-789.

8. Ferguson GT, Anzueto A, Fei R, Emmett A, Knobil K, Kalberg C. Effect of fluticasone propionate/salmeterol (250/50 microg) or salmeterol (50 microg) on COPD exacerbations. Respir Med. 2008;102(8): 1099-1108.

9. Anzueto A, Ferguson GT, Feldman G, et al. Effect of fluticasone propionate/salmeterol (250/50) on COPD exacerbations and impact on patient outcomes. COPD. 2009;6(5):320-329.

10. Decramer M, Celli B, Kesten S, et al. Effect of tiotropium on outcomes in patients with moderate chronic obstructive pulmonary disease (UPLIFT): a prespecified subgroup analysis of a randomised controlled trial. Lancet. 2009;374(9696):1171-1178.

11. Celli BR, Thomas NE, Anderson JA, et al. Effect of pharmacotherapy on rate of decline of lung function in chronic obstructive pulmonary disease: results from the TORCH study. Am J Respir Crit Care Med. 2008;178(4):332-338.

12. Jenkins CR, Jones PW, Calverley PM, et al. Efficacy of salmeterol/ fluticasone propionate by GOLD stage of chronic obstructive pulmonary disease: analysis from the randomised, placebo-controlled TORCH study. Respir Res. 2009;10:59.

13. Soriano JB, Zielinski J, Price D. Screening for and early detection of chronic obstructive pulmonary disease. Lancet. 2009;374(9691):721-732.

14. Lin K, Watkins B, Johnson T, Rodriguez JA, Barton MB; for US Preventive Services Task Force. Screening for chronic obstructive pulmonary disease using spirometry: summary of the evidence for the US Preventive Services Task Force. Ann Intern Med. 2008;148(7): 535-543.

15. Yawn BP, Mapel DW, Mannino DM, et al. Development of the Lung Function Questionnaire (LFQ) to identify airflow obstruction. Int J Chron Obstruct Pulmon Dis. 2010;5:1-10.

16. Hanania NA, Mannino DM, Yawn BP, et al. Validation of the Lung Function Questionnaire: a screener to identify risk of airflow obstruction to aid in early identification of COPD. Respir Med. 2011. In press.

17. Calverly PM, Nordyke RJ, Halbert RJ, Isonaka S, Nonikov D. Development of a population-based screening questionnaire for COPD. COPD. 2005;2(2):225-232.

18. Martinez RJ, Raczek AE, Seifer FD, et al. Development and initial validation of a self-scored COPD population screener questionnaire (COPD-PS). COPD. 2008;5(2):85-95.

19. Price DB, Tinkelman DG, Nordyke RJ, Isonaka S, Halbert RJ; for COPD Questionnaire Study Group. Scoring system and clinical application of COPD diagnostic questionnaires. Chest. 2006;129(6): 1531-1539. 
20. Van Schayck CP, Loozen JM, Wagena E, Akkermans RP, Wesseling GJ. Detecting patients at a high risk of developing chronic obstructive pulmonary disease in a general practice: cross sectional case finding study. BMJ. 2002;324(7350):1370.

21. Price DB, Tinkelman DG, Halbert RJ, et al. Symptom-based questionnaire for identifying COPD in smokers. Respiration. 2006; 73(3):285-295.

22. Kida K, Wakabayashi R, Mizuuchi T, Murata A. Screening for suspected chronic obstructive pulmonary disease with an eleven-item pre-interview questionnaire (11-Q). Intern Med. 2006;45(21):1201-1207.
23. Halbert RJ, Natoli JL, Gano A, Badamgarav E, Buist AS, Mannino DM. Global burden of COPD: systematic review and meta-analysis. Eur Respir J. 2006;28(3):523-532.

24. Mannino DM, Braman S. The epidemiology and economics of chronic obstructive pulmonary disease. Proc Am Thorac Soc. 2007;4(7): $502-506$.

International Journal of COPD

\section{Publish your work in this journal}

The International Journal of COPD is an international, peer-reviewed journal of therapeutics and pharmacology focusing on concise rapid reporting of clinical studies and reviews in COPD. Special focus is given to the pathophysiological processes underlying the disease, intervention programs, patient focused education, and self management protocols.

\section{Dovepress}

This journal is indexed on PubMed Central, MedLine and CAS. The manuscript management system is completely online and includes a very quick and fair peer-review system, which is all easy to use. Visit $\mathrm{http}: / /$ www.dovepress.com/testimonials.php to read real quotes from published authors.

Submit your manuscript here: http://www.dovepress.com/international-journal-of-copd-journal 